Addendum

\title{
Addendum: Säumel, I., et al. Edible City Solutions-One Step Further to Foster Social Resilience through Enhanced Socio-Cultural Ecosystem Services in Cities. Sustainability $2019,11,972$
}

\author{
Ina Säumel ${ }^{1,2, * \mathbb{D}}$, Suhana E. Reddy ${ }^{1}$ and Thomas Wachtel ${ }^{1}$ \\ 1 Integrative Research Institute for Transformation of Human-Environment Systems (IRITHESys), \\ Humboldt Universität zu Berlin, Unter den Linden 6, 10099 Berlin, Germany; \\ suhana.reddy@hu-berlin.de (S.E.R.); thomas.wachtel@hu-berlin.de (T.W.) \\ 2 Institute of Agricultural and Horticultural Sciences, Faculty of Life Sciences, Humboldt Universität zu Berlin, \\ Invalidenstr. 42, 10099 Berlin, Germany \\ * Correspondence: ina.saeumel@hu-berlin.de or ina.saeumel@tu-berlin.de
}

Received: 24 June 2020; Accepted: 28 June 2020; Published: 29 June 2020

check for updates

The authors would like to make the following corrections to the published paper [1]. The changes are as follows:

(1) Replacing the Acknowledgments:

Especially we want to thank Oubbol Oung (Gemeente Rotterdam, Department of Innovation, Information, Facilities and Research), Lutz Kosack (Stadtverwaltung Andernach, Department of Urban Planning and Construction Management), Cecilie Bergmann (Oslo Kommune, Agency of Urban Environment), Moritz Bellers (IBA Heidelberg) and Capote Rodríguez Amelia (Instituto de Investigaciones Fundamentales en Agricultura Tropical) for fruitful discussions on city needs (Table 1) and on the living lab ideas (Figure 3). The finally implemented Living Labs might largely differ from the drafts described here as the EdiCitNet-Living Labs will be co-created and co-implemented during the EdiCitNet project funded by the European Commission (776665). We thank the three anonymous reviewers for helpful comments and suggestions to improve this manuscript.

with

The authors acknowledge the invaluable inputs by a large number of colleagues. This paper has benefited from the writing of the two-stage grant proposal EdiCitNet, led by the authors, which is currently funded by the European Commission (Grant No. 776665). Especially, we want to thank Oubbol Oung (Gemeente Rotterdam), Lutz Kosack (Stadtverwaltung Andernach), Cecilie Bergmann (Oslo kommune), Moritz Bellers (IBA Heidelberg) and Capote Rodríguez Amelia (Instituto de Investigaciones Fundamentales en Agricultura Tropical) for fruitful discussions on city needs and on the living lab ideas. The finally implemented Living Labs might largely differ from the drafts described here, as the EdiCitNet Living Labs will be co-created and co-implemented during the EdiCitNet project (for further information please visit www.edicitnet.com). We would also like to thank the following people: Wolfgang Ansel, Andie Arndt, Natasa Atanasova, Primoz Banovec, Moritz Bellers, Franziska Bettac, Katrin Bohn, Vic Borrill, Joaquim Comas, Ferne Edwards, Mohamed El Massoudi, Sebastian Eiter, Valentin Fiala, Bernhard Freyer, Hartmut Fünfgeld, Andrej Holm, Åsmund Kaupang, Klaas Metselaar, Erwin Nolde, Oubbol Oung, Marina Pintar, Martin Regelsberger, Kristin Reichborn-Kjennerud, Marta Ruiz, Andreas Schweinberger and Emiel Wubben, who either attended 
the two EdiCitNet bid-writing workshops at TU Berlin, funded by the Bundesministerium für Bildung und Forschung (Grant No. 01UH1606A), and/or contributed conceptually, as well as methodologically and practice based to the bid writing. We thank the three anonymous reviewers for the helpful comments and suggestions to improve this manuscript.

The authors and the Editorial Office would like to apologize for any inconvenience caused to the readers by these changes. The change does not affect the scientific results. The manuscript will be updated and the original will remain online on the article webpage.

\section{Reference}

1. Säumel, I.; Reddy, S.E.; Wachtel, T. Edible City Solutions-One Step Further to Foster Social Resilience through Enhanced Socio-Cultural Ecosystem Services in Cities. Sustainability 2019, 11, 972. [CrossRef]

(C) 2020 by the authors. Licensee MDPI, Basel, Switzerland. This article is an open access article distributed under the terms and conditions of the Creative Commons Attribution (CC BY) license (http://creativecommons.org/licenses/by/4.0/). 